\title{
La moral puede enseñarse: manual teórico-práctico de la formación moral y democrática
}

\author{
Juan Carlos Gómez Rios*
}

juva8@hotmail.com

Georg Lind

Trillas, 2007

El libro de Georg Lind es un manual teórico-práctico que propone y argumenta la posibilidad de enseñar capacidades morales en los centros educativos, fundamentándose en los planteamientos de Lawrence Kohlberg (juicio moral) y poniendo en práctica un método de discusión de dilemas morales.

En la actualidad la moral no puede reducirse a elementos de valoración y buenos propósitos, mientras nuestras sociedades democráticas exigen el compromiso de reflexión y acción en nuestra realidad. Para dar respuesta a lo señalado anteriormente, Lind considera imprescindible el desarrollo de las capacidades morales que permitan aplicar correctamente los valores e ideales que necesita la persona para dar respuesta a la sociedad. En este sentido, la educación juega un papel muy importante en la consecución de dichas capacidades.

Para el autor, la educación no sólo representa el elemento que permite manejar información, conducir conocimientos y desarrollar habilidades técnicas, sino que promueve la formación de capacidades morales y democráticas propias de sociedades maduras (como lo exige la democracia) capaces de resolver y asumir sus problemáticas, dilemas y retos a través de lo racional y lo razonable.

El fundamento teórico de Georg Lind expuesto en la primera parte del libro y que da sentido a todas las ideas que va desarrollando a lo largo de dos apartados más, están relacionadas a la capacidad de juicio moral desarrollada por el psicólogo social y pedagogo estadounidense Lawrence Kohlberg, que enmarca a la moral en principios internos y comportamientos que posibilitan la toma de decisiones para favorecer la autonomía y la madurez. En este sentido una de las principales problemáticas a las que se enfrenta tanto el pensamiento de Kohlberg como de Lind es la medición de las capacidades morales, aspecto que logran resolver a través de formas de actuación concretas y tangibles. 
La segunda parte del libro hace referencia al método pedagógico de discusión de dilemas morales, en el que es importante preparar a los alumnos en la argumentación constante sobre determinados dilemas que se presentan o pueden presentarse en su contexto social, con la finalidad de fomentar la capacidad moral y democrática. En esta parte se hacen algunas recomendaciones didácticas para capacitar a los maestros en realización del método señalado anteriormente y su evaluación.00

En la tercera parte se analiza el enfoque de la comunidad democrática dentro de la escuela, el objetivo es que los alumnos puedan relacionar los valores y principios abstractos con aspectos concretos de su vida como el comportamiento que presentan ante el respeto de las normas y la justicia dentro de la institución educativa. Se propone que los alumnos, maestros y personal directivo de las instituciones tanto pequeñas como grandes puedan participar activamente en la consolidación de una comunidad educativa democrática y justa, a través de votaciones y plenarias para resolver los problemas y conflictos que atañen a la escuela.

En la parte final del libro, Lind presenta una serie de preguntas frecuentes sobre el desarrollo moral y se anexa una serie de instrumentos que permiten poner en práctica el método de discusión de dilemas morales.

Me parece que el libro tiene una estructura clara y una propuesta concreta que puede entenderse desde el título de la obra: "La moral puede enseñarse". En este sentido considero muy oportuna la forma en que el autor muestra gran interés por darle un lugar primordial a la escuela para conformar no sólo personas de conocimiento y habilidades técnicas, sino con una formación moral madura que permita hacer frente a la realidad de las sociedades.

Estoy de acuerdo con el autor al considerar que la moral tiene que responder más a las acciones y capacidades concretas que las buenas intenciones e ideales, ya que se puede observar en muchos casos que personas con problemas de delincuencia en comparación con personas que asumen sus responsabilidades cívicas pueden distinguirse más por sus acciones y capacidades que por sus buenas intenciones.

Considero que el método de la discusión de dilemas puede contribuir a que los alumnos y profesores dialoguen y sean tanto racionales como razonables, debido a la posibilidad de argumentar decisiones en casos supuestos. El problema que me viene a la mente es la diferencia entre casos casi reales y los que vivirán los alumnos, debido al nivel de presión, cuestiones tanto emocionales como condiciones de tiempo que pueden influir en la toma de decisiones. De igual 
manera considero difícil (no imposible) la posibilidad de medir capacidades morales, ya que las acciones de las personas y sus comportamientos morales se presentan en una gran diversidad de situaciones y caminos que dificultan la generalización. 